Contract No. and Disclaimer:

This manuscript has been authored by Savannah River Nuclear Solutions, LLC under Contract No. DE-AC09-08SR22470 with the U.S. Department of Energy. The United States Government retains and the publisher, by accepting this article for publication, acknowledges that the United States Government retains a non-exclusive, paid-up, irrevocable, worldwide license to publish or reproduce the published form of this work, or allow others to do so, for United States Government purposes. 


\title{
EXPERIMENTAL RESULTS FOR THE ISOTOPIC EXCHANGE OF A 1600 LITER TITANIUM HYDRIDE STORAGE VESSEL
}

\author{
J. E. Klein \\ Savannah River National Laboratory: Aiken, SC 29808, james.klein@srnl.doe.gov
}

Titanium is used as a low pressure tritium storage material. The absorption/desorption rates and temperature rise during air passivation have been reported previously for a 4400 gram prototype titanium hydride storage vessel (HSV). A desorption limit of roughly $0.25 \mathrm{Q} / \mathrm{M}$ was obtained when heating to $700^{\circ} \mathrm{C}$ which represents a significant residual tritium process vessel inventory. To prepare an HSV for disposal, batchwise isotopic exchange has been proposed to reduce the tritium content to acceptable levels.

A prototype $H S V$ was loaded with deuterium and exchanged with protium to determine the effectiveness of a batch-wise isotopic exchange process. A total of seven exchange cycles were performed. Gas samples were taken nominally at the beginning, middle, and end of each desorption cycle. Sample analyses showed the isotopic exchange process does not follow the standard dilution model commonly reported. Samples taken at the start of the desorption process were lower in deuterium (the gas to be removed) than those taken later in the desorption cycle. The results are explained in terms of incomplete mixing of the exchange gas in the low pressure hydride.

\section{INTRODUCTION}

The Savannah River Site (SRS) Tritium Facilities use a variety of metal hydrides for tritium gas processing, storage, and transportation. La-Ni-Al ("LANA") alloys are used for process gas storage, ${ }^{1}$ depleted uranium (DU) for transportation packages, ${ }^{2}$ and titanium for long term tritium storage. ${ }^{3}$ Although the concept of using titanium for tritium storage is not unique to SRS, ${ }^{4,5}$ SRS is required to remove tritium to levels sufficient for disposal.

Hydrogen isotope recovery by heated evacuation of titanium in a stainless steel vessel is limited by the temperature rating of the vessel, the vacuum speed of the pumping system, and the vacuum conductance of filters, lines, and valves. As the hydrogen isotope inventory in the titanium decreases, so does its desorption pressure.

The isotopic exchange (IX) process is commonly employed to aid in the reduction of tritium in hydrides.
The IX process dilutes the tritium with protium or deuterium and removes the mixture such that the residual tritium inventory is at an acceptable level for disposal. The purpose of this paper is to describe the "cold" (nonradioactive) experimental results using the IX process to a titanium hydride storage vessel (HSV).

\section{BACKGROUND}

As part of the development program for using titanium for long term tritium storage, two prototype HSVs (HSV-P1 and HSV-P2) were constructed for absorption and desorption testing with test results reported elsewhere. ${ }^{3}$ When the maximum desorption temperature was limited to $700^{\circ} \mathrm{C}$ for 24 hours, the residual hydrogen isotope inventory was approximately $0.28 \mathrm{Q} / \mathrm{M}^{3}$ where $\mathrm{Q}$ is the moles of hydrogen isotopes and $\mathrm{M}$ is the moles of titanium. Multi-day evacuations at $700^{\circ} \mathrm{C}$ could produce residual gas inventories in the range of 0.11 to $0.17 \mathrm{Q} / \mathrm{M}^{3}$, but these inventories still would exceed the nominal disposal limit of $37 \mathrm{TBq}(1000 \mathrm{Ci})$.

The IX equations assume complete mixing of the dilutant gas with the hydrogen isotopes in the hydride. There is good agreement between calculated IX results and experimental results for bench scale (5 gram) and multi-gram (500 to 1000 g) LANA beds and for bench scale (3 to $5 \mathrm{~g}$ ) titanium samples. ${ }^{6}$

Absorption/desorption cycling tests were conducted on HSV-P2 to determine the effectiveness of the isotopic exchange process, but the results were not presented in the previous publication. ${ }^{6}$ Application of the dilution IX model did not adequately represent the experimental data obtained from the HSV-P2 batch IX experiments. This paper is to present the HSV-P2 experimental results and explain the deviation from the dilution IX model.

\section{EXPERIMENTAL}

HSV-P2 underwent 11 absorption/desorption hydride cycles and was discussed previously. ${ }^{3}$ In summary, after the initial deuterium loading, the furnace temperature controller was set to $700^{\circ} \mathrm{C}$ and HSV-P2 desorbed for 24 
hours through both process tubes unless stated otherwise. The vessel was allowed to cool to room temperature before the next absorption cycle. Protium, the dilutant gas, was loaded into the vessel through the bottom process tube (except absorption cycle \#11) using a MFC to give an average hydride loading of $1.55 \mathrm{Q} / \mathrm{M}$. The vessel was then allowed to cool to room temperature before the start of the next desorption cycle.

The previous publication ${ }^{3}$ did not state that duplicate mass spectrometer (mass spec) "grab" samples were collected of the desorbed gas at the start of the desorption test, in the "middle" of the test, and at the end of the test. If at the end of the test the pressure was below the sample collection pressure of $1333 \mathrm{~Pa}$ (10 torr), the vessel temperature was increased slightly to obtain the samples.

\section{RESULTS}

The average hydride loading $(\mathrm{Q} / \mathrm{M})$ for HSV-P2 IX testing is shown in Figure 1 which includes when gas samples were collected. As it is illustrated in Figure 1, the $\mathrm{Q} / \mathrm{M}$ values and protium absorption rates are the same as Figure 11 in Ref. 3 with the hydride cycle number being one greater than the exchange cycle number $(\mathrm{N})$. Gas samples were taken at nominal inventories of 1.50 $\mathrm{Q} / \mathrm{M}, 0.90 \mathrm{Q} / \mathrm{M}$, and $0.28 \mathrm{Q} / \mathrm{M}$, but not taken after the $7^{\text {th }}$ exchange cycle.

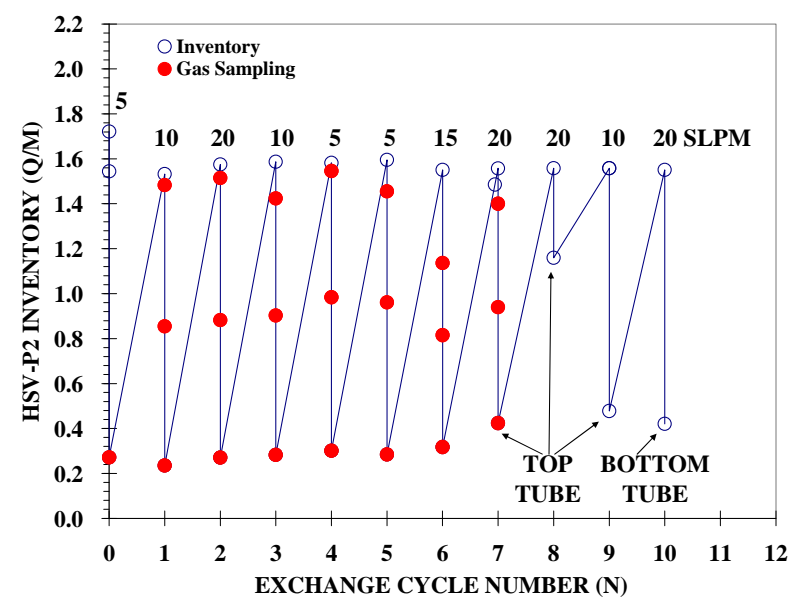

Fig. 1. HSV-P2 Exchange Test Gas Sampling

The desorbed deuterium mole fraction in the gas and hydride phase are $\left[\mathrm{y}_{\mathrm{D}}\right]_{\mathrm{D}}$ and $\left[\mathrm{x}_{\mathrm{D}}\right]_{\mathrm{D}}$, respectively. Figure 2 shows $\left[\mathrm{y}_{\mathrm{D}}\right]_{\mathrm{D}}$ versus $\mathrm{N}$ for the gas samples and the values calculated using Equation 9 of Ref. 6 The dashed line in Figure 2 will be discussed later.

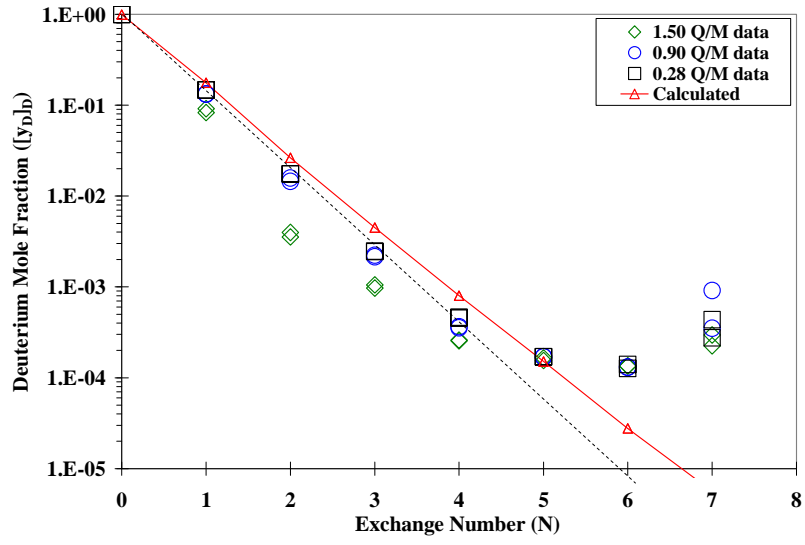

Fig. 2. HSV-P2 Exchange Results

\section{DISCUSSION}

Figure 2 shows the measured $\mathrm{y}_{\mathrm{D}}$ (dropping the subscripts for the assumed desorption conditions) values for $\mathrm{N}$ equal seven being larger than for $\mathrm{N}$ equal six. $\mathrm{N}$ equal zero through six samples were analyzed within one to three weeks of collection. Cycle seven samples where initially believed to be below the analyzer detection limit and not submitted for analysis, but were eventually analyzed approximately 68 weeks after collection. Sample storage for this duration allowed adequate time for the gas sample to interact with the uncoated wall of the sample container and alter the results. The $7^{\text {th }}$ cycle samples also had nominally $0.04 \% \mathrm{H}_{2} \mathrm{O}$ which was at least five-times higher than results for the previous cycles rendering the results suspect.

The dashed line in Figure 2 shows a faster reduction in $\mathrm{y}_{\mathrm{D}}$ versus $\mathrm{N}$ which represents a more efficient IX process, i.e. fewer exchange cycles to reach a desired gas composition. The relationship between the deuteriumprotium compositions in the gas and solid phase can be related by

$$
\begin{gathered}
y_{D}=\frac{\alpha_{D, H} x_{D}}{1+x_{D}\left(\alpha_{D, H}-1\right)} \\
\alpha_{D, H}=\frac{\left[y_{D} / y_{H}\right]}{\left[x_{D} / x_{H}\right]}
\end{gathered}
$$

where $\alpha_{D, H}$ is the separation factor. For $\alpha_{D, H}$ equal to one, the slope of the calculated line in Figure 2 is equal to fractional exchange ratio (FER, Ref. 6):

$$
F E R=\frac{[Q / M]_{D}}{[Q / M]_{A}}
$$


where the subscripts $\mathrm{D}$ and $\mathrm{A}$ define the hydride inventory at the end of the desorption and absorption, respectively. Gas transfer errors on the order of hundreds-of-standard liters would be required for the calculated line to approximate the dashed line in Figure 2 and errors of this magnitude and are not a credible explanation for the difference observed.

The dashed line in Figure 2 could be a nominal representation for at least three different scenarios. The first is a regression fit to the $0.28 \mathrm{Q} / \mathrm{M}$ sample results for $\mathrm{N}$ equal zero through four. The second scenario is for $\alpha_{\mathrm{D}, \mathrm{H}}$ set equal to 1.04. The isotope effect of protium and deuterium in Ti and the selection of $\alpha_{\mathrm{D}, \mathrm{H}}$ relevant to the IX test conditions is unclear. Some research claims no isotope effect, ${ }^{7}$ other research reports an isotope effect in the $\alpha$-phase (solubility) range, ${ }^{8,9}$ while other research reports a larger separation factor $(1 / 0.67=1.49)$ at $350^{\circ} \mathrm{C}$ for tritium-protium using a tracer technique. ${ }^{10} \alpha_{\mathrm{D}, \mathrm{H}}$ of 1.4 is needed to approximate the $1.50 \mathrm{Q} / \mathrm{M}$ data for cycles zero to three shown in Figure 2.

A $3^{\text {rd }}$ and more reasonable representation of the dashed line in Figure 2 is when the isotopic exchange process is less efficient than anticipated. In the absence of a large $\alpha_{D, H}$ value and/or large errors in the quantities of gas added or removed from the bed, the calculated line in Figure 2 represents the lower limit of $\mathrm{y}_{\mathrm{D}}$ values based on the dilution assumption in the IX calculation method. Measured $\mathrm{y}_{\mathrm{D}}$ values less than calculated values is more likely an indication that the amount of protium removed during desorption is disproportionately higher than the average protium content within the Ti.

At the end of the first desorption cycle ( $\mathrm{N}$ equal zero), the Ti is a deuterided with a concentration gradient throughout the pellet. The highest deuterium inventory is at the center and the lowest inventory being near the surface where the gas is desorbed. The bed (Ti particles) were cooled to ambient temperature before adding the protium to dilute the deuterium in the particles.

During the addition of protium to the bed during the adsorption cycle, it is believed that the protium did not completely mix/equilibrate with the residual deuterium in the Ti. Protium adsorbed by the Ti would create a high $\mathrm{H} / \mathrm{M}$ loading near the exterior of the particle, due to the low absorption pressure of titanium hydride, and if there was not a sufficient concentration and/or thermal driving force to migrate/diffuse the protium further into the particle, protium added would remain near the surface.

Before the desorption step, the outer layers of the $\mathrm{Ti}$ particles are rich in protium (lean in deuterium). As the desorption begins, this outer hydride layer produces the first gas desorbed from the Ti creating the lowest $y_{D}$ values. As the desorption continues, the Ti reaches the desorption temperature of $700^{\circ} \mathrm{C}$ and there is more time for protium and deuterium in the particles to diffuse and mix (equilibrate) within the Ti. The progressive diffusing and mixing of the isotopes produces relatively richer deuterium gas samples (leaner in protium) throughout the desorption process.

Hydride/deuteride gradients also exist throughout the HSV due to pressure and temperature gradients within the vessel. Figure 3 shows the two HSV-P2 pressure measurement points when protium was loaded for the first exchange cycle at 10 SLPM through the bottom tube of the vessel: the 10 SLPM data from Figure 12 of Ref. 6 as a semi-log plot.

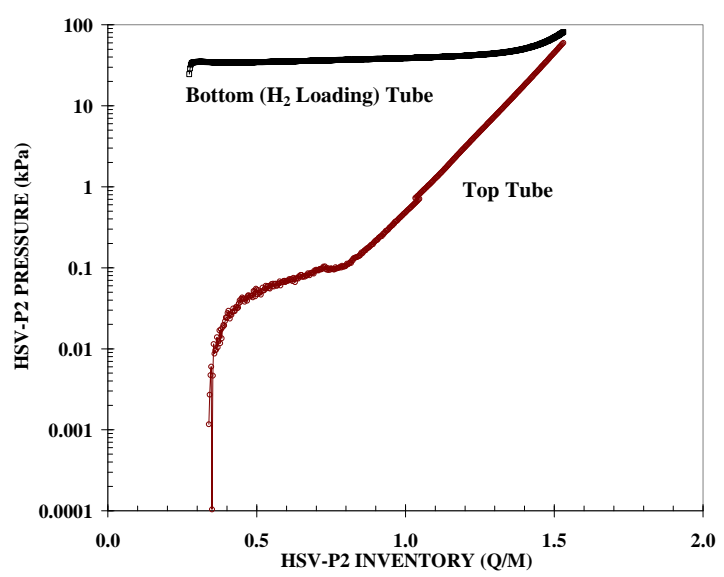

Fig. 3. Absorption Pressures During Exchange Cycle \#1

The pressure being significantly higher at the bottom (fill) location of the $\mathrm{Ti}$ packed vessel than the top indicates higher protium absorption at the bottom than at the top of the vessel. Only when the vessel has become sufficient hot from exothermic reaction does the top pressure approach the fill pressure. If gas loading continued past $1.55 \mathrm{Q} / \mathrm{M}$, the Ti could become hot enough to reduce the loading rate (based on the protium supply pressure), the pressures would be roughly equal, and the absorption rate controlled by the heat loss from the vessel.

Large temperature gradients also exist throughout the HSV when the absorption process starts at ambient temperature. During one absorption run on an HSV, an infrared camera was used to monitor the vessel's exterior temperatures. Gradients over hundreds of degrees $\mathrm{C}$ were observed and the position of the maximum temperature migrated up the vessel as the loading progressed. Internal thermal gradients were even higher, as evidenced in Figure 4, where the $\mathrm{Ti}$ particles got hot enough to agglomerate around the (bottom) fill tube of the vessel. 


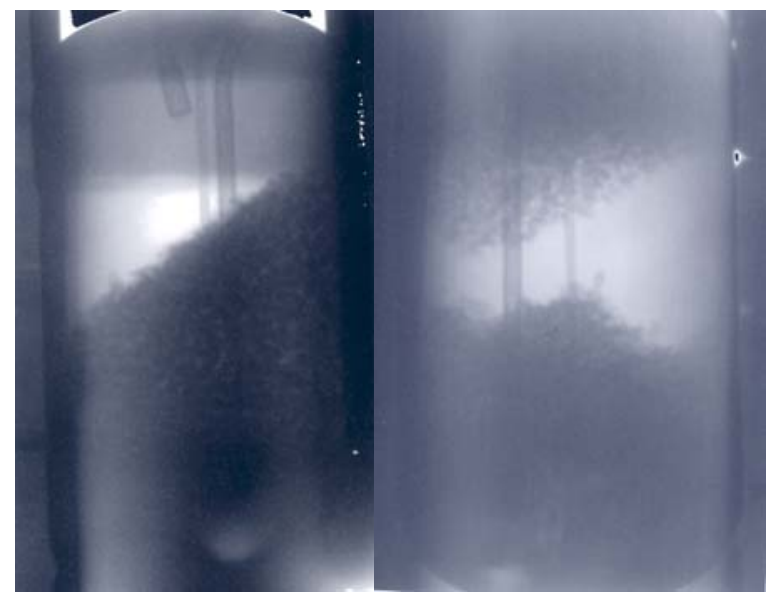

Fig. 4. HSV Radiographs Before (left, upright vessel) and After (right, inverted vessel) Loading

\section{CONCLUSIONS}

$\mathrm{y}_{\mathrm{D}}$ values calculated using the IX equations, with the well-mixed assumption for hydrogen isotopes in the solid phase, agreed with measured values for LANA alloys and bench scale Ti samples. ${ }^{6}$ This was attributed to sufficient temperature and pressure gradients to equilibrate the isotopes in the solid phase for those tests, but was inadequate to explain measured results for a multikilogram Ti vessel with up to $4.0 \mathrm{~mm}$ (5 mesh) titanium particles. The difference between calculated and measured results creates uncertainty as to the applicability of this IX technique to reduce a tritium vessel inventory below the target disposal limit.

The IX test methodology for HSV-P2 altered the results from those calculated. Large thermal and pressure gradients throughout the bed produced large variations in the gas loading of individual particles and particles at different locations within the bed. Dilutant gas addition to $\mathrm{Ti}$ particles at ambient temperature did not allow equilibration of protium and deuterium in the solid phase.

Absorption tests could be performed where the hydride is heated to an elevated temperature and the absorption pressure controlled during protium addition. Based on the diffusivity of protium and deuterium in the Ti particles, estimates could be made of the time necessary to equilibrate the isotopes within the particles, but these calculations will be reserved for future studies.

\section{ACKNOWLEDGMENTS}

The author would like to thank Jody Dye and Kit Heung of the Savannah River National Lab, and Joe
Wermer of the Los Alamos National Lab for their support of this work. This manuscript has been authored by Savannah River Nuclear Solutions, LLC under contract No. DEAC09-08SR22470 with the U.S. Department of Energy. The United States Government retains and the publisher, by accepting this article for publication, acknowledges that the United States Government retains a non-exclusive, paid-up, irrevocable, worldwide license to publish or reproduce the published form of this work, or allow others to do so, for United States Government purposes.

\section{REFERENCES}

[1] G. C. Staack, K. L. Shanahan, R. T. Walters, and R. D. Pilgrim, "Examination of $80^{\circ} \mathrm{C}$ Desorption Isotherms of Tritium Aged Pd/k and LANA.75," Fusion Sci. and Technol, 54, 85 (2008).

[2] L. K. Heung, "Tritium Transport Vessel Using Depleted Uranium,” Fusion Technol, 28, 1385 (1995).

[3] J. E. Klein, “A 1600 Liter Tritium Hydride Storage Vessel," Fusion Sci. and Technol, 41, 764 (2002).

[4] W. J. Holtslander, T. E. Harrison, V. Goyette, and J. M. Miller, "Recovery and Packaging of Tritium from Canadian Heavy Water Reactors," Fusion Technol, 8, 2473 (1985).

[5] S. Paek, D. H. Ahn, K. R. Kim, H. Chung, S. P. Yim, and M. Lee, "Performance of $500 \mathrm{kCi}$ Tritium Storage Vessel for WTRF," Fusion Sci. and Technol, 48, 75 (2005).

[6] J. E. Klein and J. R. Wermer, "Isotopic Exchange for Metal Hydride Bed Disposal," Fusion Sci. and Technol, 41, 776 (2002).

[7] R. M. Haag and F. J. Shipko, "The TitaniumHydrogen System," Proceedings of $127^{\text {th }}$ National Meeting of the American Chemical Society, Physical and Inorganic Division, Cincinnati, Ohio, p. 5155, March, 1955.

[8] K. Watanabe, "Equilibrium Pressures of Hydrogen and Deuterium Dissolved in Titanium, Zirconium, and Hafnium at Low Concentrations," J. of Nuclear Materials, 136, 1 (1985).

[9] S. Yamanaka, Y. Sato, H. Ogawa, Y. Shirasu, and M. Miyake, "Poisoning Effect on Solubility of Hydrogen Isotopes in Getter Materials," $J$. of Nuclear Materials, 179-181, 303 (1991).

[10] J. Tanaka, R. H. Wiswall, and J. J. Reilly, "Hydrogen Isotope Effect in Titanium Alloy Hydrides,” Inorganic Chemistry, 17 (2), 498 (1978). 